\title{
COMMENTARY
}

\section{The early antibiotic therapy in septic patients - milestone or sticking point?}

\author{
Michael Bernhard ${ }^{1 *}$, Christoph Lichtenstern², Christian Eckmann ${ }^{3}$ and Markus A Weigand ${ }^{2}$
}

\begin{abstract}
Sepsis is one of the oldest and most elusive syndromes in medicine. Every effort should be made to treat these patients with the best available evidence. As a milestone, empiric antimicrobial therapy is essential in order to reduce morbidity and mortality of septic patients. As a sticking point, the use of broad-spectrum antimicrobial agents may be associated with induction of resistance among common pathogens.
\end{abstract}

\section{Rationale for early antibiotic therapy}

Worldwide, the annual prevalence of sepsis is estimated at 19 million cases [1]. The mortality rates in severe sepsis were reduced to $20 \%$ to $30 \%$ because of advances in training, recognition, surveillance, monitoring, and rapid initial antibiotic therapy and organ support $[1,2]$. The most recent update of the Surviving Sepsis Campaign guidelines was published in 2013 [3]. A consensus committee provided valuable and clear recommendations on treatment of sepsis and septic shock (Table 1). One of the main focuses is the administration of a broad-spectrum antibiotic (Table 2) [3]. It is recommended that antimicrobials be administrated within the first hour of recognition of septic shock and severe sepsis without septic shock [4-7]. Moreover, it is recommended that initial anti-infective therapy include one or more drugs that have activity against all likely pathogens and penetrate in adequate concentrations into the target tissue [3]. The selected antibiotic strategy should anticipate the site of infection, medical and culture history, and local microbial susceptibility results, all in an emergency situation $[1,8]$.

\footnotetext{
* Correspondence: michael.bernhard@medizin.uni-leipzig.de ${ }^{1}$ Emergency Department, University Hospital of Leipzig, Liebigstrasse 20, D-04103 Leipzig, Germany

Full list of author information is available at the end of the article
}

\section{New research results}

\section{Appropriate antibiotic therapy}

In a systematic review and meta-analysis, Paul and colleagues [9] found a pooled odds ratio of appropriate antibiotic therapy during the first 48 hours for all-cause mortality of 1.60 (95\% CI 1.37 to 1.86 ), corresponding to a number needed to treat of 10 (95\% CI 8 to 15$)$. Kumar and colleagues [4] found a time-dependent mortality with a $7.6 \%$ decrease in survival for each hour of antibiotic delay in patients with sepsis.

\section{Timing of antimicrobial therapy}

Some recently published investigations supported the findings by Kumar and colleagues [4] (Table 3). Ferrer and colleagues [10] presented a retrospective analysis of a large dataset collected prospectively. In total, 28,150 patients with severe sepsis and septic shock from 165 ICUs in Europe, the US, and South America were included. Of them, 17,990 patients received antibiotics after identification of sepsis, and the in-hospital mortality was 29.7\%. After 1 hour, hospital mortality steadily increased with a delay in antibiotic timing. The adjusted hospital mortality odds ratios steadily increased from 1.00 to 1.52 as time to antibiotic administration increased from 0 to greater than 6 hours where 0 to 1 hour was the reference group. The probability of mortality increased from $24.6 \%$ to $33.1 \%(P<0.001)$ [10]. However, critics stated that, owing to a lack of information on antibiotic appropriateness and focus control, this study was limited [1].

In contrast, Puskarich and colleagues [11] reported results from a large prospective study of emergency department patients with septic shock, which failed to demonstrate an association between timing of antibiotic administration from emergency department triage and hospital mortality. A delay in antibiotics until after shock recognition, as compared with before, was associated with increased mortality; however, if antibiotics are administered after shock recognition, there is no increase in mortality with hourly delays. These findings were in 
Table 1 Extract of the key recommendations and suggestions of the Surviving Sepsis Campaign guidelines [3]

- $\quad$ Early quantitative resuscitation of the septic patient during the first 6 hours after recognition (1C)

- Blood cultures before antibiotic therapy (1C)

- Imaging studies performed promptly to confirm a potential source of infection (UG)

- Administration of broad-spectrum antimicrobials therapy within 1 hour of the recognition of septic shock (1B) and severe sepsis without septic shock (1C) as the goal of therapy

- Reassessment of antimicrobial therapy daily for de-escalation, when appropriate (1B)

- Infection source control with attention to the balance of risks and benefits of the chosen method within 12 hours of diagnosis (1C)

Principles of the Grading of the Recommendations Assessment, Development, and Evaluation (GRADE) system to guide assessment of quality of evidence from high (A) to very low (D) and to determine the strength of recommendations as strong (1) or weak (2). UG, ungraded.

contrast to those from Kumar and colleagues [4] and Ferrer and colleagues [10]. The differences may be explained by a higher severity of illness in the other two studies. For example, Kumar and colleagues [4] investigated ICU patients with septic shock with an overall mortality of $56 \%$ in comparison with the emergency department patients in the study by Puskarich and colleagues [11] with $19 \%$. With respect to these findings, the focus on the observed patient cohort seems to be essential.

In a prospective observational multicenter cohort study in 44 German ICUs including 1,011 patients with severe sepsis and septic shock, Bloos and colleagues [12] did not find a linear association between timing of antibiotic therapy and 28-day mortality. However, regardless of timing, 28-day mortality rate was lower in patients with adequate antibiotic therapy than in those with non-adequate antibiotic therapy (30\% versus $41 \%, P<0.001$ ). Bloos and colleagues stated that, owing to differences in the related patient populations, they were not able to confirm the findings of Kumar and colleagues [4].

Given these findings, the concept of early empiric antibiotic therapy has recently been challenged. More and more, the underlying and treated patient population has come into focus.

Table 2 Extract from the Surviving Sepsis Care bundles [3]

To be completed within 3 hours
1. Measure lactate levels.
2. Obtain blood cultures prior to administration of antibiotics.
3. Administer broad-spectrum antibiotics.
4. Administer $30 \mathrm{~mL} / \mathrm{kg}$ crystalloid for hypotension of lactate of at least
$4 \mathrm{mmol} / \mathrm{L}$.

\section{Escalating versus de-escalating strategy}

With respect to the previously reported investigations, Hranjec and colleagues [13] presented data from a 2-year, quasi-experimental before-and-after observational study of hemodynamically stable patients admitted to a surgical ICU. In the first year, patients suspected of having an infection ( $\mathrm{n}=101$, aggressive approach, de-escalating strategy) had blood cultures and antimicrobial therapy was started. In the second year, patients suspected of having an infection ( $\mathrm{n}=100$, conservative approach, escalating strategy) had an antimicrobial therapy only after objective findings confirmed an infection. The conservative approach was associated with lower all-cause mortality: (13/100) $13 \%$ versus (27/101) $27 \%, P=0.015$. The odds ratio for the risk of mortality in the aggressive approach group was 2.5 (95\% CI 1.5 to 4.0 ) in comparison with the conservative group. In this investigation, waiting for objective data to diagnose infection before treatment with antimicrobial agents for suspected infection does not worsen the mortality.

\section{Conclusions}

Early broad-spectrum antimicrobial therapy is necessary within the 'golden hour' in septic shock and, as a milestone, reduces mortality. However, the use of broad-spectrum antimicrobial agents may be associated with induction of resistance among common pathogens and therefore may be a sticking point. In septic patients without sepsis-associated hypotension, diagnostic measure may be beneficial before an antibiotic therapy starts. New research is urgently needed concerning different strategies that would balance early administration of antibiotics against the potential harmful effects to patients and resistance. New research strategies have to test a de-escalating strategy with restriction of specific broad-spectrum antibiotics in the initial therapy to the most critically ill patients and patients with suspicion of multidrug-resistant pathogens, against an escalating strategy in less critically ill patients. Moreover, further studies are needed to distinguish between more and less critically ill patients, to differentiate patients' backgrounds, and to determine indicators for patients who profit from an escalating or de-escalating strategy.

Competing interests

The authors declare that they have no competing interests.

\section{Authors' contributions}

All authors read and approved the final manuscript.

\section{Author details}

'Emergency Department, University Hospital of Leipzig, Liebigstrasse 20, D-04103 Leipzig, Germany. ${ }^{2}$ Department of Anesthesiology, University Hospital of Heidelberg, Im Neuenheimer Feld 110, D-69120 Heidelberg, Germany. ${ }^{3}$ Department of General, Visceral and Thoracic Surgery, Academic Hospital of Medical University Hannover, Virchowstrasse 8h, D-31221 Peine, Germany. 
Table 3 Comparison of studies investigating antibiotic treatment in patients with sepsis

\begin{tabular}{|c|c|c|c|c|c|c|}
\hline Parameter & $\begin{array}{l}\text { Kumar et al. [4] Crit } \\
\text { Care Med (2006) }\end{array}$ & Ferrer et al. [10] Crit Care Med (2014) & $\begin{array}{l}\text { Puskarich et al. [11] } \\
\text { Crit Care Med (2011) }\end{array}$ & $\begin{array}{l}\text { Bloos et al. [12] } \\
\text { Crit Care (2014) }\end{array}$ & \multicolumn{2}{|c|}{$\begin{array}{l}\text { Hranjec et al. [13] Lancet } \\
\text { Infect Dis (2012) }\end{array}$} \\
\hline Study design & $\begin{array}{l}\text { Retrospective multicenter } \\
\text { cohort study }\end{array}$ & $\begin{array}{l}\text { Retrospective analysis of prospective } \\
\text { collected dataset multicenter }\end{array}$ & $\begin{array}{l}\text { Prospective preplanned analysis of a } \\
\text { multicenter randomized clinical trial }\end{array}$ & $\begin{array}{l}\text { Prospective multicenter } \\
\text { cohort study }\end{array}$ & \multicolumn{2}{|c|}{$\begin{array}{l}\text { Prospective quasi-experimental, } \\
\text { before-and-after observational } \\
\text { study single center }\end{array}$} \\
\hline \multirow[t]{2}{*}{ Setting } & \multirow[t]{2}{*}{ ICU septic shock } & \multirow[t]{2}{*}{ ICU mixed } & \multirow[t]{2}{*}{ ED septic shock } & \multirow[t]{2}{*}{ ICU } & \multicolumn{2}{|c|}{ ICU-acquired infection } \\
\hline & & & & & Aggressive & Conservative \\
\hline Patients & 2,731 & 17,993 & 291 & 1,011 & 247 & 237 \\
\hline Age, years & 63 & NR & $62(I Q R$ 50-73) & 69 & NR & NR \\
\hline Gender, male & $54 \%$ & NR & $53 \%$ & $63 \%$ & NR & NR \\
\hline APACHE score & $26 \pm 9$ & NR & NR & $N R$ & NR & $N R$ \\
\hline SAPS ॥ & NR & NR & $42(I Q R$ 30-55) & $48(I Q R$ 37-60) & $N R$ & $N R$ \\
\hline SOFA score & NR & NR & $6(\mathrm{IQR} 4-9)$ & 10 (IQR 8-12) & NR & $N R$ \\
\hline MEDS score & NR & NR & 11 (IQR 8-14) & NR & NR & NR \\
\hline Septic shock & $2,731(100 \%)$ & $11,558(64.2 \%)$ & $291(100 \%)$ & NR & $38.5 \%$ & $46.4 \%$ \\
\hline Positive BC & $34.2 \%$ & NR & $100(34.4 \%)$ & $317(48.8 \%)$ & $N R$ & $N R$ \\
\hline Nosocomial & $58.1 \%$ & $12.2 \%$ & $N R$ & $56.2 \%$ & $N R$ & $N R$ \\
\hline $\begin{array}{l}\text { Median time to } \\
\text { shock recognition }\end{array}$ & NR & NR & 89 (IQR 48-180) & NR & $N R$ & $N R$ \\
\hline Overall mortality & $56.2 \%$ & $31.3 \%$ & 55 (18.9\%) & $41.4 \%$ & 99 (40.1\%) & $50(21.1 \%)$ \\
\hline $\begin{array}{l}\text { Mortality for } \\
\text { BC-positive septic } \\
\text { shock }\end{array}$ & NR & NR & 26/100 (26.0\%) & NR & NR & NR \\
\hline $\begin{array}{l}\text { Mortality for } \\
\text { BC-negative } \\
\text { septic shock }\end{array}$ & NR & NR & 29/191 (15.2\%) & NR & $N R$ & NR \\
\hline \multicolumn{7}{|l|}{ Infection site } \\
\hline Pneumonia & $1,016(37.2 \%)$ & $8,487(47.2 \%)$ & 99 (34.0\%) & 351 (34.9\%) & 75 (20\%) & 93 (39\%) \\
\hline UTI & $293(10.7 \%)$ & $4,757(26.4 \%)$ & 71 (24.4\%) & $122(12.1 \%)$ & $33(13 \%)$ & $36(15 \%)$ \\
\hline Intra-abdominal & 801 (29.3\%) & 3,505 (19.5\%) & 49 (16.8\%) & $366(36.3 \%)$ & 31 (13\%) & $22(9 \%)$ \\
\hline Skin and soft tissue & $197(7.2 \%)$ & $1,133(6.3 \%)$ & $23(7.9 \%)$ & NR & NR & NR \\
\hline Intravascular catheter & $100(3.7 \%)$ & $661(3.7 \%)$ & $11(3.8 \%)$ & NR & $14(6 \%)$ & $8(3 \%)$ \\
\hline Surgical wounds & $31(1.1 \%)$ & 815 (4.5\%) & $7(2.4 \%)$ & NR & $19(8 \%)$ & $21(9 \%)$ \\
\hline Endocarditis & NR & $187(1.0 \%)$ & $4(1.4 \%)$ & NR & $N R$ & NR \\
\hline CNSI (e.g., meningitis) & $20(0.7 \%)$ & $277(15 \%)$ & $3(1.0 \%)$ & NR & NR & NR \\
\hline Septic arthritis & $21(0.8 \%)$ & NR & $2(0.7 \%)$ & NR & NR & $N R$ \\
\hline SDI & 58 (2.1\%) & NR & $1(0.3 \%)$ & NR & NR & NR \\
\hline
\end{tabular}


Table 3 Comparison of studies investigating antibiotic treatment in patients with sepsis (Continued)

\begin{tabular}{|c|c|c|c|c|c|c|}
\hline Ear, nose, throat & $N R$ & NR & $1(0.3 \%)$ & NR & $N R$ & $N R$ \\
\hline Toxic shock syndrome & NR & NR & $1(0.3 \%)$ & NR & NR & NR \\
\hline Unknown & $120(4.4 \%)$ & NR & $40(13.8 \%)$ & $50(5 \%)$ & $49(20 \%)$ & $46(19 \%)$ \\
\hline Two or more sources & $N R$ & NR & $21(7.2 \%)$ & NR & $N R$ & $N R$ \\
\hline Mediastinitis & $15(0.5 \%)$ & NR & $N R$ & NR & $N R$ & $N R$ \\
\hline Other & $59(2.1 \%)$ & $1,980(11.0 \%)$ & NR & $105(10.4 \%)$ & $26(11 \%)$ & $11(5 \%)$ \\
\hline Bone & $N R$ & $232(1.3 \%)$ & NR & NR & $N R$ & $N R$ \\
\hline Device & NR & $219(1.2 \%)$ & NR & $N R$ & $N R$ & $N R$ \\
\hline Bone/soft tissue & $N R$ & NR & NR & $72(7.1 \%)$ & $N R$ & NR \\
\hline Upper airway & $N R$ & NR & NR & $83(8.2 \%)$ & $N R$ & NR \\
\hline
\end{tabular}

APACHE, Acute Physiology and Chronic Health Evaluation: BC, blood culture; CNSI, central nervous system infection; ED, emergency department: IOR, interquartile range: MEDS, Mortality in Emergency Department Sepsis; NR, not reported; SAPS II, Simplified Acute Physiology Score II; SDI, systemically disseminated infection; SOFA, Sequential Organ Failure Assessment; UTI, urinary tract infection. 


\section{Published online: 30 November 2014}

\section{References}

1. Van Zanten AR: The golden hour of antibiotic administration in severe sepsis: avoid a false start striving for gold. Crit Care Med 2014, 42:1931-1932.

2. Angus DC, van der Poll T: Severe sepsis and septic shock. N Engl J Med 2013, 369:840-851.

3. Dellinger RP, Levy MM, Rhodes A, Annane D, Gerlach H, Opal SM, Sevransky JE, Sprung CL, Douglas IS, Jaeschke R, Osborn TM, Nunnally ME, Townsend SR, Reinhart K, Kleinpell RM, Angus DC, Deutschman CS, Machado FR, Rubenfeld GD, Webb S, Beale RJ, Vincent IL, Moreno R, Surviving Sepsis Campaign Guidelines Committee including The Pediatric Subgroup: Surviving Sepsis Campaign: international guideline for management of severe sepsis and septic shock, 2012. Intensive Care Med 2013, 39:165-228.

4. Kumar A, Roberts D, Wood KE, Light B, Parrillo JE, Sharma S, Suppes R, Feinstein D, Zanotti S, Taiberg L, Gurka D, Kumar A, Cheang M: Duration of hypotension prior to initiation of effective antimicrobial therapy is the critical determinant of survival in human septic shock. Crit Care Med 2006, 34:1589-1596.

5. Ferrer R, Artigas A, Suarez D, Palencia E, Levy MM, Arenzana A, Pérez XL, Sirvent JM, Edusepsis Study Group: Effectiveness of treatments for severe sepsis: a prospective, multicenter, observational study. Am J Respir Crit Care Med 2009, 180:861-866.

6. Barie PS, Hydo LJ, Shou J, Larone DH, Eachempati SR: Influence of antibiotic therapy on mortality of critical illness caused or complicated by infection. Surg Infect 2005, 6:41-54.

7. Castellanos-Ortega A, Suberviola B, García-Astudillo LA, Holanda MS, Ortiz F, Llorca J, Delgado-Rodríguez M: Impact of the surviving sepsis protocols on hospital length of stay and mortality in septic shock patients: results of a three-year follow-up quasiexperimental study. Crit Care Med 2010, 38:1036-1043.

8. Pinder M, Bellomo R, Lipman J: Pharmacological principles of antibiotic prescription in critically ill patients. Anaesth Intensive Care 2002, 30:134-144.

9. Paul M, Shani V, Muchtar E, Kariv G, Robenshtok E, Leibovici L: Systematic review and meta-analysis of the efficacy of appropriate empiric antibiotic therapy for sepsis. Antimicrob Agents Chemother 2010, 54:4851-4863.

10. Ferrer R, Martin-Loeches I, Phillips G, Osborn TM, Townsend S, Dellinger RP, Artigas A, Schorr C, Levy MM: Empiric antibiotic treatment reduces mortality in severe sepsis and septic shock from the first hour: results from a guideline-based performance improvement program. Crit Care Med 2014, 42:1749-1755.

11. Puskarich MA, Trzeciak S, Shapiro NI, Arnold RC, Horton JM, Studnek JR, Kline JA, Jones AE, Emergency Medicine Shock Research Network (EMSHOCKNET): Association between timing of antibiotic administration and mortality from septic shock in patients treated with a quantitative resuscitation protocol. Crit Care Med 2011, 39:2066-2071.

12. Bloos F, Thomas-Rüddel D, Rüddel H, Engel C, Schwarzkopf D, Marshall JC, Harbarth S, Simon P, Riessen R, Keh D, Dey K, Weiß M, Toussaint S, Schädler D, Weyland A, Ragaller M, Schwarzkopf K, Eiche J, Kuhnle G, Hoyer H, Hartog C, Kaisers U, Reinhart K, MEDUSA Study Group: Impact of compliance with infection management guidelines on outcome in patients with severe sepsis: a prospective observational multi-center study. Crit Care 2014, 18:R42.

13. Hranjec T, Rosenberger LH, Swenson B, Metzger R, Flohr TR, Politano AD, Riccio LM, Popovsky KA, Sawyer RG: Aggressive versus conservative initiation of antimicrobial treatment in critically ill surgical patients with suspected intensive-care-unit-acquired infection: a quasi-experimental, before and after observational cohort study. Lancet Infect Dis 2012, 12:774-780.

doi:10.1186/s13054-014-0671-

Cite this article as: Bernhard et al:: The early antibiotic therapy in septic patients - milestone or sticking point? Critical Care 2014 18:671. 